\title{
Moral Responsiveness and Discontinuity in Therapy: A Qualitative Study
}

Jason B. Whiting PhD

Brigham Young University, jason.whiting@byu.edu

R. Scott Nebeker

ACS, Inc.

Stephen T. Fife

University of Nevada, Las Vegas

Follow this and additional works at: https://scholarsarchive.byu.edu/facpub

Part of the Psychoanalysis and Psychotherapy Commons

\section{Original Publication Citation}

Whiting, J. B., Nebeker, R. S., \& Fife, S. T. (2005). Moral responsiveness and discontinuity in therapy: A qualitative study. Counseling and Values, 50, 20-37

\section{BYU ScholarsArchive Citation}

Whiting, Jason B. PhD; Nebeker, R. Scott; and Fife, Stephen T., "Moral Responsiveness and Discontinuity in Therapy: A Qualitative Study" (2005). Faculty Publications. 2172.

https://scholarsarchive.byu.edu/facpub/2172

This Peer-Reviewed Article is brought to you for free and open access by BYU ScholarsArchive. It has been accepted for inclusion in Faculty Publications by an authorized administrator of BYU ScholarsArchive. For more information, please contact ellen_amatangelo@byu.edu. 


\title{
Moral Responsiveness and Discontinuity in Therapy: A Qualitative Study
}

\begin{abstract}
Jason B. Whiting, R. Scott Nebeker, and Stephen T. Fife
Phenomenological qualitative methods were used to identify and describe moral elements in therapeutic relationships. Using the relational philosophy of E. Levinas (1961/1969, 1979/1987) as a base, data in which therapists and clients identified and described morally responsive experiences in therapy sessions were analyzed. These moments were often unexpected and included categories of surprise, interruption, willingness to change, and clarifications/repairs. Additional moral phenomena related to therapists' attitudes included asymmetrical indebtedness, attitude of serving. and tentativeness of diagnosis. Identified moments of moral responsiveness were frequently associated with clients' progress in therapy. This suggests that conceptually smooth and uninterrupted therapy may be less helpful than therapy that is discontinuous and able to change in the moment.
\end{abstract}

\section{$\mathrm{T}$} herapists have historically been taught to remain neutral with clients and to use theories built on seemingly objective foundations of medicine and science. Moral concerns in therapy have been devalued or ignored because they are seen as imprecise and subjective (Slife, 1993). Yet conversations between therapist and client are often suffused with moral reflection, making "psychotherapy an ideal moral laboratory" (Doherty, 1995, p. 18). Therapy frequently deals with right and wrong behavior, making choices, and finding happiness. However, moral concerns common to individuals and relationships have traditionally been left out of the professional conversation, leaving therapeutic language void of moral content (Bergin, 1980). As Williams and Gantt (2002) have noted, "Because of its unfortunate adoption of natural scientific epistemology ... contemporary psychology is singularly ill-equipped to account for human action in any manner that might preserve its essentially moral character" (pp. 10-11).

Although the discipline has historically avoided the moral domain, the culture and science of therapy are changing. Therapists and researchers (e.g., Doherty, 1995; Fishbane, 1998; Kunz, 2002) are recognizing a need for more discussion of moral issues. In addition, methodological and philosophical developments allow questions of morality in therapy to be asked more directly than ever before (Denzin \& Lincoln, 2000; Peterson \& Seligman, 2004). Clarifying the role of morality in therapy could lead to a better understanding of the influence of moral behavior of therapists and clients. In addition, understanding moral influence might allow for greater use of moral interventions and language.

Jason B. Whiting, Department of Family Studies, University of Kentucky; R. Scott Nebeker, ACS, Inc., Lexington, Kentucky; Stephen T. Fife, Department of Marriage, Family, and Community Counseling, University of Nevada, Las Vegas. Correspondence concerning this article should be addressed to Jason B. Whiting, 315 Funkhouser Building, Lexington, KY 40506 (e-mail: jason.whiting@uky.edu). 
This study was a qualitative investigation of therapeutic interactions from a perspective sensitive to the moral nature inherent in human face-to-face encounters. We explored morality from the viewpoint of clients, therapists, and observers, using the following research questions:

1. How does morality present itself phenomenologically in the way therapists and clients respond in therapeutic relationships?

2. What sorts of interventions and therapeutic events are associated with morally responsive moments?

The philosophical work of Emmanuel Levinas $(1961 / 1969,1979 / 1987)$ was used to understand and describe these moral interactions. The results of this study lend support to the importance of understanding morality and moral discourse in therapeutic settings (Urofsky \& Engels, 2003; Williams \& Gantt, 2002).

\section{Philosophical and Theoretical Foundations}

Various philosophical and theoretical traditions in psychology have treated morality in different ways. Models of therapy that are influenced by modernist philosophies might describe morality as in the individual, in that people are moral inherently, rationally, or by conditioning. For example, psychodynamic theories associate morality with rigid societal strictures that cause repression and stunt growth. Morality, therefore, is something imposed on an individual by society and that is enforced internally via the superego. Similarly, behaviorism might frame moral issues as ethics that individuals are conditioned to accept in order to live in society. True morality is not possible according to these modernist theories because action is a product of internal drives or external stimuli rather than being a choice between alternatives of different value (Williams, 1992).

Another influential theoretical school that intersects with moral issues is humanism. This tradition, associated with scholars such as Carl Rogers and Abraham Maslow, attempts to soften the hard determinism of psychoanalytic and behaviorist theory by advocating a caring and client-centered approach to therapy (Crenshaw, 2004). Humanists value individual worth and experience and see people as agents-able to choose and grow according to what is best for the individual. Rogers (1970) called this innate tendency to grow an organismic valuing process. Although humanism promotes caring and acceptance, as a theory, it encounters some dilemmas in grappling with moral concerns.

The first dilemma that arises relates to the humanist conception of inborn and inner needs that drive one's growth and behavior. If these tendencies, which Maslow (1968) compared to instincts, govern behavior, then the dilemma of whether there is true agency reemerges (see Slife \& Williams, 1995, for a full treatment of this issue). It is not clear how innate tendencies can control behavior and still allow for agency. When behavior is not freely chosen, it loses its moral nature. The second problem is that in pursuing individual needs and potential, morality becomes individualistic and relativistic. Slife and 
Williams stated the humanist dilemma this way: "If our needs ought to be pursued, and if they are unique to us, then we ought to be judged and held accountable only for whether we are acting true to our own needs" (p. 37).

A third, and related, concern is that nonjudgmental therapy can lead to acceptance of immoral behavior in clients. For example, the nonjudgmental position of humanists greatly influenced the value-neutral tradition of psychotherapy (Crenshaw, 2004). Supportive and nonjudgmental therapists sometimes encourage decisions that are harmful (Doherty, 1995). This is somewhat ironic, in that Rogers himself did not practice in a value-neutral manner (Truax, 1966). More recent humanistic models of therapy have attempted to address humanism's lack of advocacy or willingness to make moral judgments (Madanes, Keim, \& Smelser, 1995; Price \& Keim, 1993). Although humanism's contribution of valuing clients and recognizing individual worth was important, humanism has struggled to adequately grapple with moral dilemmas that occur in therapeutic relationships and in the lives of clients. An alternative philosophy is needed that can address these moral issues in a scholarly and careful way.

\section{The Philosophy of Levinas}

The work of Levinas $(1961 / 1969,1979 / 1987)$ offers philosophical grounding that is well suited to understanding morality. Levinas's work is not founded on Western philosophy and modernistic traditions. These have traditionally first asked the question "What exists?" and then, based on the answer, "What is right?" Levinas suggested that ethics (the good, morality) precedes and grounds the possibility for ontology (what really exists). His approach suggested a different epistemology -one that tries to understand human existence by seeking the ethical as revealed in relationships. This is also different from postmodern traditions that see morality as between individuals. Postmodern schools, such as social constructionism, assert that people are moral inasmuch as they relate, communicate, and form society (Gergen \& Gergen, 2000). By this definition, it would be impossible for a person to be moral without others, but Levinas takes the relational grounding of morality a step further. "Levinas's work presents a genuine and radical alternative to both traditional approaches to psychology and their postmodern alternatives. It offers a grounding for human being and human action in which meaning and morality are not reduced or relativized" (Williams \& Gantt, 2002, p. 30).

Levinas's work is well suited for understanding the inherent moral nature of therapeutic relationships (e.g., Halling, 1975; Hand, 1992; Vandenberg, 1999). Levinas accounted for the morality in modern and postmodern therapies, solving the conundrums of each while providing a description that is coherent, consistent, and comprehensive. Levinas showed that morality cannot come from principles and reason. He accounted for the instinctive good of humanism through a perspective captured in his phenomenology of the Other. Levinas agreed with postmodernists who locate the moral in the social linguistic world. However, he avoided the relativistic implications of their theories by grounding the ethical world in relationships. These relationships are prior to ontol- 
ogy, metaphysics, and language. A brief description of Levinas's history, philosophy, and terminology helps clarify how his work can help illuminate the moral content in the therapeutic process.

A survivor of a Nazi prisoner of war camp, Levinas experienced the totalizing horror and violence under systems of thought that craft explanations and justifications about superior kinds of beings (ontology). Levinas argued that morality cannot derive from ontology but must precede it. He also asserted that individuals' ability to act comes from the relationships that they have with others. With others, individuals have two options: They can respond ethically, which leads to more freedom and moral interaction, or they can respond out of their preconceived notions, categories, and pathology (totalization), which leads to bondage and isolation. This choice, which is posed to individuals by the presence or face of another person, is defined by Levinas (1961/1969) as the call of the Other. Warner (2001) described this summoning:

From the countenance of every individual . . comes the imperative, "Treat me as a person separate from yourself, but just as real-with hopes and needs of my own." Or to use the words of . . . Kant, "Treat me as an end and not as a means." If we will hearken to this summons and do as it dictates, we will change in our relation to those people... we will care for them and resonate with them. (p. 171)

Traditional science seeks explanations that reduce differences and predict behaviors. This method of investigating human phenomena eliminates the alterity (or differentness) of the Other. An alternative to this scientific totalization is an inquiry in which people do not assume they understand (in the sense of capture or possess) the Other. By recognizing the impossibility of fully comprehending another, individuals always remain tentative. They are invited to keep conceptions under constant revision as they continually converse with the Other. When the conversation stops, the tendency is to reduce the Other (e.g., the client's reality) to the same (e.g., the therapist's preconceptions). This is an example of totalization.

According to Levinas, it is within language that human beings have a relationship. In a truthful conversation, the alterity of the Other is appreciated, not eliminated. Discourse is kept alive by continuing the conversation with openness to the Other. The most truthful mode of discourse is this interactive process during which objectifications and totalitarian judgments are questioned. This is why a science that recognizes moral phenomena as valid would be tentative about its explanations--those explanations can and must continually be remade in the ongoing conversation.

Therapy is also an example of the ethical encounter because it involves people who attempt to effect a cure through talking. The continual renewal of therapist-client interaction creates a living relationship in which experiencing the Other in new or unexpected ways is part of the process. Levinas called these moments the epiphany of the Other, where the same (the therapist) recognizes the humanity of the person he or she is with. This may occur as a therapist experiences respect, inspiration, or a feeling of obligation to the client. Stern (2003) has argued that better language is needed to describe therapeutic experiences of this type, in which sudden feelings, intuitive ideas, or shifts in relational 
action occur. Sometimes this type of in-the-moment response can occur without logical reason or therapeutic rationale. Acting on this intuitive feeling may be difficult when a moral prompting deviates from the therapist's plan or treatment model. Levinas offered a framework for understanding this type of moral responsiveness as it relates to the therapeutic conversation. The call of the Other may preempt " $m y$ " plan and invite a response. Thus, shifts and surprises in therapy offer a moral choice.

\section{Morality and Moral Responsiveness}

Moral responsiveness may be defined in several ways (Pearce, 1998). This study defines it as the degree of truthfulness with which a person is able to respond to another and the sense of responsibility that comes when experiencing the alterity of the Other. Moral responsiveness might be called a "way of being," with similarities to Buber's "I-Thou" position (Fishbane, 1998; Warner, 2001). A morally responsive therapist has the attitude described by the Levinasian term primacy of the Other, showing a concern for all that pertains to the Other. In addition, morally responsive persons are truthful in that they willingly accept the responsibility that comes from authentically relating with others (Williams, 1992).

Mental health professions have always incorporated aspects of morality into their work, although not always explicitly. For example, ethics codes emphasize conduct that is founded in the morality of a culture, and the good character of a therapist has been assumed to be essential for professional success (Bednar \& Kaul, 1994). As early as the 1960s, therapists were arguing that psychotherapy should be explored within a moral rather than medical context, and various voices have debated the role of morality in therapy for several decades (e.g., Doherty, 1995; Lageman, 1993). Moral responsiveness extends this dialogue by suggesting that therapeutic opportunities regularly present themselves in ways that would not fit a typical theoretical or even caring script. A morally responsive therapist (regardless of theoretical persuasion) is willing to abandon the script as needed. Our attempt to clarify morality as it is manifest in therapists' responsiveness is a logical step in better understanding how and when this might be important to therapy.

\section{Research Methods and Procedure}

Qualitative experts Denzin and Lincoln (2000) have defined the future of research as one of moral discourse. They suggested that the contextual sensitivity of qualitative methods is well suited to studying human moral interaction. Stiles (1994) summarized the strengths of qualitative inquiry as being "linguistic, empathic, contextual, polydimensional, and nonlinear" that facilitates a "more tentative epistemology than that of hypothesis testing research" (p. 159). Denzin and Lincoln presented five phases of qualitative research. Phase 1 identifies the researchers, Phase 2 explicates the theoretical paradigm of the study, Phase 3 specifies the research strategy, Phase 4 states the methods used for data collection and analysis, and Phase 5 describes the interpretation and presentation of the study. 
We (White men with doctoral degrees from different institutions who work in a variety of professional settings-clinical practice, academia, and business) conducted the research. One motivation to do the research was a desire to fill a gap in traditional psychological discussion regarding morality and obligation to others. This gap includes a lack of professional language describing spiritual and moral phenomena in relationships (including therapy). We believe that such phenomena are part of therapeutic experience but assert that these concepts have been afforded scant discussion in the therapeutic literature. We agree that moral concerns deserve serious intellectual discussion (e.g., Polkinghorne, 1999; Williams \& Gantt, 2002).

\section{Phase 2: Theoretical Paradigms and Perspectives}

Every investigation, regardless of method, proceeds from an epistemological stance (Slife \& Williams, 1995). Often this stance is hidden within language that implies objectivity of both the theory and researcher (Knapp, 2002). Qualitative research recommends that method and assumptions be disclosed for contextual evaluation. The theoretical foundation for this project shares many elements of postpositivism, critical theory, and constructivism but includes a moral grounding as well. Specifically, these new elements include (a) the word truthful in epistemology and ontology (Williams, 1992), (b) ethics seen as more fundamental than ontology (Levinas, 1961/1969), and (c) moral participation with others in the research project (Stiles, 1994).

This research, which we define as a phenomenological hermeneutic study, involved exploring and interpreting phenomena in dialectical interchange between investigators and research participants. Ultimate answers to research questions were forsaken in exchange for illumination and articulation. Established research guidelines were followed to ensure valid and trustworthy descriptions (Lincoln \& Guba, 2000). Following this strategy required that assumptions and conclusions remained tentative as ideas and theoretical perspectives changed during the research process.

\section{Phase 3: Research Strategies}

Participants in this study consisted of four therapists and five clients. One therapist worked with two participating clients, the others with one client each. This small purposive sample was chosen to accomplish the methodological goal of saturation of a specific phenomenon as it manifested itself across several cases and sessions (Ryan \& Bernard, 2000). Therapists were two wellseasoned professionals (more than 20 years in practice) as well as two doctoral students, each using a variety of theoretical approaches in his or her practice. Clients were a 31-year-old woman presenting with relationship problems; a 19-year-old woman with depression and relationship difficulties; a 21-yearold man with identity difficulties and depression; a 36-year-old woman with problems of depression and social isolation; and a 24-year-old woman with problems of impulse control, depression, and self-mutilation. 


\section{Phase 4: Methods of Collection and Analysis}

Data collection. The interviews were conducted by the second author at the campus clinic of a religiously affiliated university. Therapist-client dyads were studied through the use of videotape-assisted interviewing (Elliott \& Shapiro, 1992; Martin, 1992). Immediately after each therapy session, clients and therapists filled out a short questionnaire describing the moments in therapy that they found most and least helpful (Paulson, Truscott, \& Stuart, 1999). Therapists and clients were interviewed separately and were asked to report their in-session experiences as they watched videotaped segments of therapy identified as most and least helpful (Kvale, 1996). Often, participants would comment on watching themselves on tape, and these comments were included in the research data. They were asked additional questions about their experiences related to hypothesized moral phenomena. Approximately 16 sessions of data were collected from each of the five clients. Sixty-nine hours of therapy sessions were matched with 50 hours of debriefing, for a total of 119 hours of videotape. All sessions and debriefings were transcribed, which resulted in a page count of approximately 1,200 pages.

Analysis. The immersion/crystallization technique, as defined by Miller and Crabtree (2000), consists of cycling between text and interpretation, making connections until the investigator is confident enough of the interpretation to construct a report. Positive and negative examples of therapeutic effectiveness and moral responsiveness were compared and contrasted with each other as the analysis proceeded. Salient themes and categories emerged, and these were refined and explored with subsequent interviews. The organization of the themes was facilitated by the use of computer software as the process continued.

\section{Phase 5: Interpretation and Presentation}

In exploratory research of this nature, the recursive process between a select sample of participants and the researcher is part of effectively capturing the "essence of experience" (Ryan \& Bernard, 2000, p. 780) of the phenomena being studied. Following the procedure suggested by Stiles (1994), a narrative report describing and synthesizing the data from all three perspectives (client, therapist, observer/investigator) was shown to therapists, and their comments were collected and integrated into the analysis. This led to the finalizing of thematic categories and arranging of them according to their relationships. The therapists again reviewed the results with the interviewer, and their comments were also integrated into the final report.

\section{Results}

Our purpose was to identify morally responsive aspects of therapy. Although some of the resulting themes may not seem overtly moral, they were related to processes and attitudes that reflected ethical obligations in the face-to-face therapeutic encounters: That these elements were woven throughout many aspects of therapy reinforced the usefulness of this process. Therapists often 
do not recognize the moral elements in their work, and when they do, they may be unsure how to appropriately respond to them (Lageman, 1993). These results suggest that morality is embedded throughout the clinical process in both relational and individual ways. The primary thematic categories that emerged from this study are (a) morally responsive relational phenomena (surprise, interruption, change of approach, and clarifications/repairs) and (b) attitudes of morally responsive therapists (including asymmetrical indebtedness, attitude of serving, and tentativeness of diagnosis).

\section{Morally Responsive Relational Phenomena}

Surprise. It was anticipated that morally responsive therapists would experience moments of awe or wonder when clients exceeded the therapist's conceptions and expectations. An I-Thou stance facilitates an openness to being surprised and appreciative of another (Fishbane, 1998). In our research, this occurred for both clients and therapists. Therapists' surprise often related to experiencing clients in a different way than their previous understanding or expectation of them: "I was surprised that I felt so strongly about her staying alive. ... It overcame me." Such surprises were usually associated with allowing one's preconceived notions to be changed. Other surprises were related to seeing clients change in response to intervention.

Occasionally, therapists did things that surprised both clients and themselves. In one incident, a therapist followed a hunch and abruptly changed the topic, which caught the client off guard. The client remembered,

He said, "Let me suggest that those aren't the problems," and it made a whole lot of sense. ... We were talking about something totally different, and then he just turns and talks about something we've never talked about before.

Another client said, "I was surprised at some of the questions he was asking because they were the right questions to be asking me, and I was kind of thinking, 'How'd you figure that out?'"

Interruption. Therapeutic events in which therapists were open to the interruption of a preconceived notion or direction illustrate a moral willingness to change. Interruption differs from surprise in that it is generally an unbidden aspect of therapy. We found that attending to interruptions was sometimes corrective for therapists who may have been reducing the client's experiences to inaccurate or oversimplified conclusions. Participating therapists were also interrupted in their sessions by changing client presentations, loss of therapeutic gains, disruptions in the therapeutic relationship, and transference issues. One said, "[S]he does a kind of transference thing. It's kind of weirdlike her sister was in love with my brother or something." Clients also experienced interruption, such as when they were presented with alternative interpretations of their lives. This is illustrated by a client who ruminated upon a therapist's statement: "[She made] a comment about my being set up to fail. ... It's just sort of stuck in my mind. Almost haunted me. I'll find it popping back into my head when I'm doing other things." 
Change of approach. Being open to surprises and interruptions creates an opportunity for therapists to change in response to the Other. In this study, therapists often altered their approach in sessions. During those incidents, the therapists reported feeling that it was the right thing to do. Often they had theoretical justifications for the alteration in approach; at other times, they attributed their certainty to personal inspiration or epiphany. When the direction being pursued felt unhelpful, one therapist said, "I changed my focus [to be] less analytic, less intervention. ... I needed to be right there with her." Abandoning a psychodynamic interpretive technique for a more supportive stance, he took a pragmatic approach:

I came to it basically just out of the situation. I think this is a time where she has some momentum and direction. She's finally started to move [and] I don't see it as a time to stop and go back, but rather to support her right here and now. . . I don't know if there's any way to explain it beyond common sense. You have to be there and know, get a sense of what the person is doing and what they need at the time.

In reflecting on this incident, the therapist identified this change as emerging from a sense of being stuck, and then being inspired with what needed to happen:

The clarity emerged. But I don't know-did it emerge from our interaction, did I feel a prompting? Inspiration from God? It was a sense that I needed to act, and that it needed to be action with respect to the core of her being.

In the moments before this epiphany and subsequent change in direction, the therapist struggled. Therapy had ground to a halt, and the therapist was seeking something new: "I was probing in my mind for something different and in that moment came the different idea." The surprise that led to this change of approach was not the impasse, but the emotion the therapist felt when the solution came.

Without moral responsiveness, the previous therapist might have taken a different turn at the point of impasse or might have dismissed the impasse altogether. Without the desire to act "with respect to the core of her being," other therapists might blame the impasse on resistance or the client's failure to respond to intervention and consequently might have missed the opportunity to act in a way that led to a successful outcome. Upon reflection, both therapist and client often identified the same moments as significant. For example, a client had a turning point when she found the therapist becoming more "human and vulnerable." The therapist described this same moment as a time when she felt "this real genuine sense of liking for [the client]."

Clarifications and repairs. An interesting finding in our research was that therapists' mistakes (such as failing to listen or botching an intervention) often led to better therapeutic alliances as the mistakes were addressed and resolved. Clarification and repairs occurred as therapists opened themselves to the Other and demonstrated a willingness to learn and be corrected. For example, one therapist made a comment about a client not being normal, which upset the client: "Right then I panicked and totally detached from [the therapist]. And there was no way I was gonna interact with her. I was just too threatened." In this incident, the client was presented with alternatives about whether 
she would take further risks with the therapist or abort therapy. Such events provided opportunities for the client to work through the relationship issues that were at the core of her therapy. Through these repeated interchanges, the client chose to continue to interact rather than withdraw and ultimately reached a successful outcome. This case illustrates the "sloppy" (Stern, 2003, p. 56) process of therapy, whereby growth occurs by resolving the inevitable surprises and misunderstandings in therapeutic relationships.

In many of these cases, the miscommunications that occurred in the normal course of therapy seemed helpful in the end because they precipitated a clearer understanding of the relationship. In each case, the dynamic involved the therapist missing important moments, followed by the client's reaction that increased the therapist's awareness. The therapist then had an opportunity to clarify and revisit the issue and come to a more truthful understanding of the client. The client had the opportunity to attempt interpersonal risks with the therapist by helping the therapist understand what happened. Insecure therapists who are focused on their own fragile sense of competence rather than on the Other may miss these opportunities.

\section{Attitudes of Morally Responsive Therapists}

Asymmetrical indebtedness. Feeling responsible for another person without expecting a reciprocal response is the essence of asymmetrical indebtedness. It involves an attitude or willingness to be open to the feelings of valuing or respecting the Other. These are spontaneous feelings that transcend reason, but they may be the most human elements in therapy. These are moments of impact, awe, and reverence when one feels the responsibility for the Other by virtue of the relationship. Feelings of asymmetrical indebtedness emerged in the therapy sessions, and these experiences often correlated with important changes in therapy. One therapist described being overwhelmed with a client: "I was kind of smiling and thinking, 'It's amazing to listen to herhow complex, how multifaceted she is.' That's another thing that makes me respect her." Discovering the personhood of clients seemed to be an important component of helping them feel safe to take risks in therapy. One therapist gave an example of how this was critical when working with a victim of sexual abuse:

A female client comes in and has kind of broad assumptions about men. And they will come in and kind of discount your masculinity: "Well, you're not a man. You're my counselor." But there comes a point where that client connects with you as a person, and their experience with you can't be explained away. I think the part that you bring to that as a counselor is that you refuse to see the client in the way that most people see the client. So it's kind of a two-way thing. You're helping them to overcome their typing of you or typing of men or whatever it is that they're typing. And then I think the struggle for the counselor is to try to do the same thing, to get to the person beneath the pathology.

This sense of obligation in asymmetrical indebtedness moves beyond the Rogerian valuing and unconditional positive regard to a moral commitment. One therapist referred to this as "meta-empathy," which is more of a spiritual responsibility for the person: 
My role is to peel back the scales of oppression that are caused by pathology-you know, circumstances, inheritance, ignorance, and so forth, and to open his eyes and to help him be in touch with the [spiritual] inner core of himself.

Attitude of serving. Whereas asymmetrical indebtedness is a spontaneous feeling of awe or respect, an attitude of serving connotes a willingness to value the Other and his or her uniqueness. It involves an obligation to seek the Other's needs before one's own. The opposite of an attitude of serving might occur when therapists (a) use a client out of curiosity (such as pursuing a story for selfgratification), (b) force a client's responses into a favorite theoretical framework, (c) subsume the personhood of a client with a diagnostic label, or (d) manipulate clients for personal power or control. This is illustrated by one client's comments about feeling objectified and devalued by a former therapist:

\footnotetext{
Like one guy I saw . . . when I was talking to him, it seemed like he just had everything really planned out ... like I wasn't really that important. I felt like I was a test case to them. Like they were seeing if they could win this one, seeing if they could fix this problem, and then OK, on to the next. And that made me feel like their ego would go up if they could fix me or something. Whereas with [current therapist], it feels like he actually cares, you know. I'm sure the others cared a little bit, but I think their satisfaction came from themselves being, "Oh, I'm so good, you know, and I can fix blah blah blah."
}

In general, therapists' experiences of obligation were moderated by the severity and complexity of the case. With more severe cases, therapists felt a stronger responsibility to do more to ensure a good outcome. Most of these therapists did not accept the implications of the word obligated and preferred responsible in constructing their responses. This may be because of the traditional connotations of obligation, which are more rigid than obligation in Levinasian parlance. As a result, the idea of being a servant who is responsible to help the client was somewhat discrepant with the role that therapists saw themselves fulfilling. Several clarified their sense of responsibility. One said,

I feel responsible in the relationship, and I feel responsible to be honest with her. I feel responsible to give her my full attention and really work when I'm with her and think about what's going on and try to help her.

In another case, the therapist was considering hospitalizing the client. The therapist was fatigued, and the client had not progressed. The therapist resisted serving the client:

It's a struggle for me between being selfish and not being selfish. ... I don't want to put her in the hospital. ... It's work, just so much work. And so that's why I don't want to put her in the hospital, and that's selfish. That means it clouds my judgment.

This therapist sought spiritual strength regarding what would be best for the client and felt a responsibility that came with feeling as if she were a spiritual "conduit."

Another therapist discussed a willingness to be vulnerable with her severely disordered clients: "I really have to be as close to the person's psychic process as I can be." She explained that the risk was necessary to understand the client as well as to gain his or her trust. The cost, however, was a series of nightmares she had that were related to this client's family. In a different interview, the same therapist described this cost of therapist openness: 
For me, making a moral choice means putting my own needs second. And my needs are to be competent and professional and to look in charge and, when I'm with her, I will have to be the expert. That's important. But in order to be moral, I will have to be vulnerable. That is hard, because that opens me up to nightmares at night, and I have dreams about her. And, very concretely, in that therapy hour, it opens me up to having to say things like "I don't know what you're talking about. I'm lost." Or "Oh yeah, I guess that was pretty harsh. I apologize." Or "Yeah, I shouldn't have given you an IQ test. It was just downright rotten of me." You feel bad for months.

In this instance, we see a therapist demonstrating an attitude of serving by sacrificing comfort that comes with professional distance. This commitment to serving seemed to grow from experiences with asymmetrical indebtedness described earlier.

Tentativeness of diagnoses. Forcing the uniqueness and depth of a person into a diagnosis is an example of totalization. We hypothesized that morally responsive therapists would avoid rigidly categorizing their clients. Could morally responsive therapists maintain their focus on the client as Other rather than reducing him or her to a set of symptoms in need of intervention? Even though the therapists in this study represented a variety of approaches and experience levels, none used diagnoses in any rigid way. Rather, most had a variety of pragmatic uses for diagnoses in practice that were based on their own experience. Some therapists found diagnosis helpful for broad distinctions between serious disorders. As one seasoned therapist said, "Diagnoses [are] fluid. ... I have yet to see anybody who is a pure type." Most therapists wrestled with questions regarding the usefulness of diagnoses. Some used rules of thumb such as "The most useful differentiation I make is between mood disorders, [or] long-standing kinds of problems." Another therapist thought that the traditional diagnostic categories were insufficient.

\section{Discussion}

The analysis of these interviews and observations provided many therapeutic examples that could be described as morally responsive. The participants readily identified morally responsive moments and attitudes, and they appreciated the chance to describe these often unnamed experiences. Some suggested synonyms for moral responsiveness, such as authentic, congruent, inspired, spiritually responsive, and emotionally responsive. When reviewing the initial report, one therapist said that these findings confirmed her experience over many years as a therapist, teacher, and researcher - that good therapy requires (a) therapists who love (agape) their clients, (b) therapists who receive inspiration, and (c) therapists who have the courage to act on the inspiration to make appropriate interventions.

An interesting result of this study was the pervasiveness of therapeutic discontinuity. Although this research was an investigation of people responding in the moment (which implies shifting or changing), it was surprising to see the prevalence of discontinuous action throughout the sessions. Some of the most helpful and unhelpful moments in therapy were discontinuous in nature. Clients were better and worse suddenly and unexpectedly. At times, therapists abruptly changed their tactics and therapeutic approaches, responding to their "gut instinct," hunches, or inspiration. These results question the assumption that a straightforward application of a therapy model; sequen- 
tial interventions; and steady, consistent progress in therapy are the norm. Even for seasoned professionals, the therapeutic process had many unexpected developments and shifts that occurred "in the moment" in sessions.

Perhaps the discontinuous nature of moral responsiveness helps explain the difficulty the counseling profession has in discussing and classifying these in-the-moment experiences. Such moments do not fit well in the mechanical models that are at the foundation of the therapeutic professions (Slife, 1993). As a result, therapists end up considering these experiences part of the "art" of psychotherapy that is not discussed theoretically.

Levinas $(1979 / 1987)$ has helped therapists understand discontinuity by suggesting that time is fundamentally discontinuous because the possibility to act is given to us by the Other. In Levinasian terms, our research data illustrated times when the client became the Other to the therapist, and the therapist responded to that "Otherness." Perhaps Levinas has provided a linguistic and philosophical bridge for newer psychotherapy theories that more closely describe the experiences of therapists and clients.

\section{Implications for Clinicians}

Therapists are in a unique line of work. Many are drawn to this type of helping profession because of personal values rather than innate technical strengths (Fife \& Whiting, 2005). Society has historically assumed that therapists ought to have certain moral strengths, such as caring or integrity (Bednar \& Kaul, 1994), and has looked to psychotherapy for moral direction (Doherty, 1995). Yet the counseling professions spend little time helping therapists develop or understand the influence of moral areas. New research on virtues and character strengths may help researchers and practitioners appreciate the relationship between these attributes and professional competence (Peterson \& Seligman, 2004). This study offers several such suggestions for therapists who are hoping to increase the moral sophistication of their work. The following discussion offers some clinical applications related to both the discontinuous morally responsive relational phenomena (surprise, interruption, change of approach, and clarifications and repairs) and therapist attributes (asymmetrical indebtedness, attitude of serving, and tentativeness of diagnosis).

To be surprised or interrupted, therapists must engage in interaction with a client and construct an expectation of that person. Then, the therapist must be open enough to notice discrepancies between the client's presentation and the therapist's expectations. Therapists should remain tentative in understanding a client because there is always more to the person than the therapist's conception can contain. Surprises may build on and enhance the therapist's perceptions and reaffirm the course of intervention. This differs from interruptions, which offer therapists an opportunity to review and modify their intervention strategies. Therapists should watch for moments when preconceived notions are interrupted by the reality of the Other. Levinas's suggestion that the face of the Other will interrupt the therapist implies that therapists may, at times, be forcibly corrected by a client's interruption. The possibility of interruption and surprise in sessions 
suggests that therapists should pay particular attention to the moment-tomoment process in therapy rather than focusing inordinately on past experiences or on a plan or theory to which they have committed themselves.

There may be times when therapists pursue their own agenda because of insecurity, theoretical bias, or discomfort with emotional content. However, it is likely that therapists who are willing to change their approach if needed will more readily achieve therapist-client congruence, which clients recognize and appreciate (Quinn, 1996). Although it is challenging for two to steer a vessel at the same time, the interactive negotiations between therapist and client are part of what keeps therapy on a useful trajectory. Therapists can be more aware of the cocreated struggle inherent in the relationship and the moments when they are tempted to ignore the call of the Other.

For clinicians, it may also be helpful to view diagnoses as narratives that arrange and simplify the observations, provide information about their occurrence, and suggest a course of action. Because they are narratives, no single diagnosis can be considered correct or incorrect based on some metaphysical criteria. Rather, diagnoses would be judged according to their helpfulness, and some diagnoses might be modified or discarded. Where such categorization is necessary (e.g., insurance reimbursement), a morally responsive therapist might hold those ideas tentatively, ready to let the label of a diagnosis be interrupted by the Otherness of the client.

"It is benevolence that permits the therapist to join with the client and exert the necessary level of personal influence, even in very difficult cases such as domestic violence, child abuse and sexual molestation" (Crenshaw, 2004, p. 27). In cases like these, it may be that the most moral choice is not to support and normalize client's behavior, but to problematize it. Although it may be more comfortable to remain neutral, challenging clients to see the consequences of their behavior could help them improve their morality in their relationships (Crenshaw, 2004). By refusing to accept immoral behavior, the therapist is modeling morality to clients: caring for them by holding them accountable. If a therapist remains neutral or accepting of immoral (harmful to self or others) behavior, he or she is being dishonest in a Levinasian sense (Williams, 1992).

A truthful interaction occurs where the therapist seeks to do what the client needs in the moment rather than what the therapist needs. When therapists are motivated to serve the Other, they may act in a variety of ways, but the intent will likely come across to the client. As an example, consider the "honest feedback" that is actually a mask for therapist frustration, such as when a therapist is reactive toward a client but then blames the client for his or her own reactivity ("I was just giving him the hard truth"). The underlying motivation, rather than the behavior itself, defines whether the behavior is moral.

\section{Implications for Research}

Phenomenological work is designed to generate in-depth results from a small sample of participants so that subsequent researchers can apply these findings with broader samples of therapists and clients (Ryan \& Bernard, 2000). Although moral discourse is not easily measured in psychotherapy research, 
refining the parameters of moral responsiveness through the development of psychometrically sound instruments could be helpful. If moral responsiveness were to be operationalized and tested conceptually, it might correlate with current measures of therapist attributes, yet it would likely provide additional moral or spiritual dimensions. Would those who are highly developed in certain therapist attributes score higher in morally responsive measures? It may be that when people are morally responsive, they score higher on measures of working alliance, empathy, and engagement because they are real people engaging in a moral discourse with others whom they respond to and respect. It might also be interesting to further explore how therapists follow their intuition or are influenced by conceptual frameworks. Therapists make a wide variety of choices about therapeutic interventions: Knowing why might make explicit much that currently is not discussed in the professional literature.

Much of the moral interaction correlated with shifts in therapy; therefore, scholars could focus on discontinuities as a starting point for future research. For instance, one valuable avenue of inquiry might be to explore instances when therapists felt prompted to act a certain way because of a hunch and then measure the impact in terms of therapeutic outcome. It may be that the difference between effective and less effective therapists is the courage to act on inspiration, as long as it is tempered by the wisdom of experience and common sense.

The prevalence of discontinuity as it relates to responsive moments also offers important directions in future research on process. "Because the process of chaining together... relational moves and present moments is largely spontaneous and unpredictable ... there are many mismatches, derailments, misunderstandings, and indeterminacy [in therapy]" (Stern, 2003, p. 55). Observing how therapists and clients transform these therapeutic mishaps into breakthroughs could be helpful in understanding effective therapy. There may be an association between the effectiveness of therapy and how therapists navigate the mistakes and corrections in the therapeutic relationship. New rating scales or questionnaires might be useful in understanding the effects of these shifts as they occur in session.

There may also be correlations between how connected the therapist felt with the client (as conceptualized by asymmetrical indebtedness or an attitude of serving) and outcome. There is a need to further differentiate conceptually the attitude of serving with being overly responsible (due to therapist self-focus or insecurity). Better understanding this way of being could help therapists balance their personal commitment to clients with the tendency to objectify clients for personal needs. One hypothesis is that therapists' unresolved personal issues might interfere with their ability to be open to the client.

Using the philosophy of Levinas $(1961 / 1969,1979 / 1987)$ as a foundation for the study provides an example for others who are seeking alternative ways of understanding and describing the therapeutic encounter. Philosophies that are grounded in ethics and relationships offer possibilities for studying moral constructs. For example, Kunz (2002) has argued that Levinas has created a philosophical bridge that allows psychologists to study the good in human behavior. Kunz suggested that "psychologists cannot find altruism because they do not know how to look for it" (p. 119) because of a reliance on Western 
philosophy. Using the language of Levinas has helped therapists see morality in the therapy room, where it has traditionally remained hidden.

\section{Limitations}

The act of researching the therapeutic process inevitably changes that process (Miller \& Crabtree, 2000). Although this occurs with all types of research, it is important to reflect on how the observing changes the phenomena being observed. The impact of the research on the therapeutic process was assessed throughout the course of this study. Several times during the interviews, clients requested that their therapist be made aware of content that had arisen during a debriefing. This interaction then became a focus of therapeutic discussion.

There were several incidents when participating clients asked that the videotaping of the interview be stopped. One therapist chose to stop discussing a sensitive issue and alter the level of disclosure because the comments would be preserved. Another therapist asserted that participating in the research helped increase her awareness and fight the mistakes that can happen when fatigue sets in. One client had a difficult time noticing the therapist's nonverbal support when she was in session, but instead discovered it while reviewing the tape. In general, clients and therapists expressed the helpful nature of being able to review the sessions and contents with the researcher.

It is also important to acknowledge the interactive and interpretive nature of qualitative research. Different researchers would have brought forth different socially constructed content. We recognize that the phenomena in question have a risk of self-confirmation. Specifically, it is possible that the search for morally responsive phenomena in therapists will produce examples of it. In addition, this project involved participants from one community. Although the goal of phenomenological work is rich description rather than generalization to a population, another setting with other researchers would produce variations on these findings.

\section{Conclusion}

Moral aspects of human behavior are important experiences that define individuals and give their lives meaning. Human beings are relational creatures, and morality is centered in relationships. Yet articulating how morality manifests itself in therapy has been somewhat elusive. This study has provided support for the importance of understanding the therapist's way of being, not just the therapist's actions. The moral attitude and responsiveness of the therapist will affect the nature of the professional relationship, which may, in turn, influence the results of therapy. It is important for therapists to understand that their own moral responsiveness in session has consequences in the lives of the clients they serve.

\section{References}

Bednar, R. L., \& Kaul, T. J. (1994). Experiential group research: Can the canon fire? In A. Bergin \& S. Garfield (Eds.), Handbook of psychotherapy and behavior change (pp. 631-663). New York: Wiley. 
Bergin, A. E. (1980). Psychotherapy and religious values. Journal of Consulting and Clinical Psychology, 48, 95-105.

Crenshaw, W. (2004). Treating families and children in the child protective system: Strategies for systemic advocacy and family healing. New York: Brunner-Routledge.

Denzin, N. K., \& Lincoln, Y. S. (2000). Introduction: The discipline and practice of qualitative research. In N. Denzin \& Y. Lincoln (Eds.), Handbook of qualitative research (2nd ed., pp. 1-28). Thousand Oaks, CA: Sage.

Doherty, W. J. (1995). Soul searching: Why psychotherapy must promote moral responsibility. New York: Basic Books.

Elliott, R., \& Shapiro, D. A. (1992). Client and therapist as analysts of significant events. In S. G. Toukmanian \& D. L. Rennie (Eds.), Psychotherapy process research (pp. 163186). New York: Aronson.

Fife, S. T., \& Whiting, J. B. (2005). Values in family therapy research and practice: $A$ call for reflection. Unpublished manuscript.

Fishbane, M. D. (1998). I, thou, we: A dialogical approach to couples therapy. Journal of Marital and Family Therapy, 24, 41-58.

Gergen, M. M., \& Gergen, K. J. (2000). Qualitative inquiry: Tensions and transformations. In N. Denzin \& Y. Lincoln (Eds.), Handbook of qualitative research (2nd ed., pp. 10251046). Thousand Oaks, CA: Sage.

Halling, S. (1975). The implications of Emmanuel Levinas' totality and infinity for therapy. In A. Giorgi, C. Fischer, \& E. Murray (Eds.), Phenomenological psychology Vol. II (pp. 206-223). Pittsburgh, PA: Duquesne University Press.

Hand, S. (1992). Introduction. In S. Hand (Ed.), The Levinas reader (pp. 1-8). Cambridge, England: Blackwell.

Knapp, S. J. (2002). Authorizing family science: An analysis of the objectifying practices in family science discourse. Journal of Marriage and Family, 64, 1038-1048.

Kunz, G. (2002). Simplicity, humility, patience. In E. E. Gantt \& R. N. Williams (Eds.), Psychology for the Other: Levinas, ethics and the practice of psychology (pp. 118-142). Pittsburgh, PA: Duquesne University Press.

Kvale, S. (1996). Interviews: An introduction to qualitative research interviewing. Thousand Oaks, CA: Sage.

Lageman, A. G. (1993). The moral dimensions of marriage and family therapy. New York: University Press of America.

Levinas, E. (1969). Totality and infinity (A. Lingis, Trans). Pittsburgh, PA: Duquesne University Press. (Original work published 1961)

Levinas, E. (1987). Time and the Other (R. Cohen, Trans.). Pittsburgh, PA: Duquesne University Press. (Original work published 1979)

Lincoln, Y. S., \& Guba, E. G. (2000). Paradigmatic controversies, contradictions, and emerging confluences. In N. Denzin \& Y. Lincoln (Eds.), Handbook of qualitative research (2nd ed., pp. 163-187). Thousand Oaks, CA: Sage.

Madanes, C., Keim, J. P., \& Smelser, D. (1995). The violence of men: New techniques for working with abusive families: $A$ therapy of social action. San Francisco: Jossey-Bass.

Martin, J. (1992). Cognitive-mediational research on counseling and psychotherapy. In S. G. Toukmanian \& D. L. Rennie (Eds.), Psychotherapy process research (pp. 108-133). New York: Aronson.

Maslow, A. H. (1968). Toward a psychology of being (2nd ed.). New York: Van Nostrand Reinhold.

Miller, W. L., \& Crabtree, B. F. (2000). Clinical research. In N. Denzin \& Y. Lincoln (Eds.), Handbook of qualitative research (2nd ed., pp. 607-631). Thousand Oaks, CA: Sage.

Paulson, B. L., Truscott, D., \& Stuart, J. (1999). Clients' perception of helpful experiences in counseling. Journal of Counseling Psychology, 46, 317-325.

Pearce, F. (1998). In a perfect world: The moral responsibility of therapists. The Humanist, $58(3), 39-41$.

Peterson, C., \& Seligman, M. E. P. (2004). Character strengths and virtues: A handbook and classification. New York: Oxford University Press. 
Polkinghorne, D. (1999). Foreword. In J. Martin \& J. Sugarman, The psychology of human possibility and constraint (pp. vii-xiv). Albany: State University of New York Press.

Price, J. A., \& Keim, J. (1993). Introduction to special edition on strategic humanism. Journal of Systemic Therapies, 12, 1A-1B.

Quinn, W. H. (1996). The client speaks out: Three domains of meaning. Journal of Family Psychotherapy, 7, 71-93.

Rogers, C. R. (1970). Toward a modern approach to values: The valuing process in the mature person. In J. T. Haar \& T. M. Tomlinson (Eds.), New directions in client-centered therapy (pp. 430-441). Boston: Houghton Mifflin.

Ryan, G. W., \& Bernard, H. R. (2000). Data management and analysis methods. In N. Denzin \& Y. Lincoln (Eds.), Handbook of qualitative research (2nd ed., pp. 769-802). Thousand Oaks, CA: Sage.

Slife, B. D. (1993). Time and psychological explanation. Albany: State University of New York Press.

Slife, B. D., \& Williams, R. N. (1995) What's behind the research? Discovering hidden assumptions in the behavioral sciences. Thousand Oaks, CA: Sage.

Stern, D. S. (2003, November/December). The present moment. Psychotherapy Networker, 52-57.

Stiles, W. B. (1994). Views of the chasm between psychotherapy research and practice. In P. F. Talley, H. H. Strupp, \& S. F. Butler (Eds.), Psychotherapy research and practice: Bridging the gap (pp. 154-166). New York: Basic Books.

Truax, C. B. (1966). Reinforcement and nonreinforcement in Rogerian psychotherapy. Journal of Abnormal Psychology, 71, 1-9.

Urofsky, R. I., \& Engels, D. W. (2003). Philosophy, moral philosophy, and counseling ethics: Not an abstraction. Counseling and Values, 47, 118-131.

Vandenberg, B. (1999). Levinas and the ethical context of human development. Human Development, 42, 31-32.

Warner. C. T. (2001). Bonds that make us free: Healing our relationships, coming to ourselves. Salt Lake City, UT: Shadow Mountain.

Williams, R. N. (1992). The human context of agency. American Psychologist, 47, 752-760.

Williams, R. N., \& Gantt, E. E. (2002). Pursuing psychology as a science of the ethical: Contributions of the work of Emmanuel Levinas. In E. E. Gantt \& R. N. Williams (Eds.), Psychology for the Other: Levinas, ethics and the practice of psychology (pp. 1-31). Pittsburgh, PA: Duquesne University Press. 
Copyright of Counseling \& Values is the property of American Counseling Association. The copyright in an individual article may be maintained by the author in certain cases. Content may not be copied or emailed to multiple sites or posted to a listserv without the copyright holder's express written permission. However, users may print, download, or email articles for individual use. 